\title{
A finite element model with discrete embedded elements for fibre reinforced composites
}

\author{
Vítor M.C.F. Cunha ${ }^{\mathrm{a}, 1, *}$, Joaquim A.O. Barros ${ }^{\mathrm{b}, 1}$, José M. Sena-Cruz ${ }^{\mathrm{b}, 1}$ \\ ${ }^{a}$ Department of Engineering, School of Science and Technology, University of \\ Trás-os-Montes e Alto Douro, 5001-801 Vila Real, Portugal \\ ${ }^{b}$ Department of Civil Engineering, School of Engineering, University of Minho, \\ 4800-058 Guimarães, Portugal
}

\begin{abstract}
This work presents a numerical approach to simulate the behaviour of steel fibre reinforced concrete, FRC. The adopted strategy comprises three main steps: i) assessing the fibre pullout behaviour; ii) generation of "virtual" fibre structures and iii) modelling FRC as a two-phase material. The concrete phase is simulated with a smeared crack model, while the fibre's positioning and orientation correspond to the fibre phase and are obtained from step ii. Finally, the fibre reinforcement mechanisms are modelled with the micromechanical behaviour laws obtained in step i. The agreement between the numerical and experimental results revealed the high predictive performance of the developed numerical strategy.
\end{abstract}

Keywords: FEM, Fiber reinforced concrete, Smeared crack model, Embedded discrete element

\section{Introduction}

Within steel fibre reinforced concrete, SFRC, steel fibres and matrix are bonded together through a weak interface. This interface behaviour is important to understand and accurately model the mechanical behaviour of 5 SFRC, since the properties of this composite are greatly influenced by fi6 bre/matrix interface and, consequently, by the micro-mechanical fibre rein-

\footnotetext{
*Corresponding author.

Email address: vcunha@utad.pt; vcunha@civil.uminho.pt (Vítor M.C.F. Cunha)

${ }^{1}$ ISISE - Institute for Sustainability and Innovation in Structural Engineering
} 
forcement mechanisms that are mobilised during fibre pullout. For these composites, when reinforced with low fibre volume ratios, the fibre contribution benefits arise mainly, not to say almost exclusively, after the crack initiation.

The post-cracking behaviour of random discontinuous fibre reinforced brittle-matrix composites can be predicted by the use of a stress - crack opening displacement relationship, $\sigma-w$. In the case of SFRC, the $\sigma-w$ relationship can be approximated by averaging the contributions of the individual fibres bridging the matrix crack plane [1-4]. One difficulty concerning the prediction of the post-cracking behaviour of SFRC in a real structure is that the material behaviour in a test specimen may differ from the behaviour of a real structural element. It is well described in literature that various casting procedures and structural shapes may result in predominant fibre orientation into parallel planes $[5,6]$. In the case of steel fibre reinforced self-compacting concrete, SFRSCC, the predominant fibre orientation can be along the flow itself (in the fresh state) and along the boundary surfaces due to the wall effect [7-9]. The fibre orientation near the walls of a structural element is not representative of the material, but of a structure [5]. A predefined orientation of the steel fibres parallel to the tensile direction in a test specimen may result in overestimating the post-cracking mechanical properties of SFRC, when compared with specimens with equal amount of fibres, however with a random fibre orientation.

Having in mind this brief introduction of the principal aspects and factors that influence and contribute to the post-cracking behaviour of SFRC, approaching SFRC as a continuum material may lead to a crude and, even, incorrect estimation of the mechanical behaviour of a certain SFRC structural element. Even though material behaviour laws for SFRC can be obtained with great accuracy by inverse analysis procedures of test specimens, these laws may not translate the accurate material behaviour within a specific structural element, due to the aforementioned factors that influence the behaviour of this material [10].

Steel fibre reinforced composites can be regarded as a two-phase material made up of an unreinforced concrete matrix phase and a fibre phase. The contribution of the fibre phase to the composites' post-cracking behaviour is quite more important than the matrix phase. Thus, it is essential that the fibre phase comprises accurate information about the fibre structure's density and orientation, which depends on where and how the material is applied. Adopting this approach can somehow enhance the numerical simulation of 
SFRC structures, thus excluding the use of biased material behaviour laws, e.g. laws obtained from inverse analysis procedures.

Therefore, based on the prior reasoning, in the present work a numerical approach is detailed where SFRC is treated as a heterogeneous medium composed of one homogeneous phase (aggregates and paste), and another one composed of the steel fibres. The fracture process of the cementicious matrix (unreinforced) is modelled with a fixed smeared crack model. This unreinforced concrete phase is discretised by solid finite elements. On the other hand, the stress transfer between crack planes due to the reinforcing mechanisms of fibres bridging active cracks is modelled with 3D embedded elements. A nonlinear behaviour law is assigned to these last elements in order to account for the fibre/matrix interface properties. These laws are based upon the results obtained from fibre pullout tests [11]. The random fibre distribution, over the matrix, is simulated with an algorithm based on the Monte Carlo method, providing a realistic distribution of the fibres over a bulk element. The developed algorithm takes into account factors that influence the fibre structure as is the case of the so-called wall effect and the high flowability of SFRSCC. The geometry, positioning and orientation of the fibres are subsequently inserted in a three dimensional finite element mesh. The linear elements representing the fibres are considered as embedded elements. Since the stiffness of the embedded elements may not be homogeneously and isotropically distributed over the intersected "parent" elements (i.e. solid elements that discretise the concrete phase), an inverse mapping algorithm was developed and implemented to enable the accurate assessment of the fibre's nodal forces.

In the past decades, several models for embedded elements have arisen either for two-dimensional [12-14] and three-dimensional cases [15, 16] differing in their complexity, regarding either the material behaviour (full bond or bond - slip capability) or geometry/positioning of the embedded elements (fixed or arbitrary shape and positioning). The formulation of the embedded fibre model developed in this work does not take into account fibre bond slip behaviour in a direct fashion. Within a first stage of the research, as a simplification, the embedded element is modelled with a perfectly bonded formulation. Hence, the bond - slip behaviour is simulated in an indirect fashion from the transformation of a load - slip relationship to a tensile stress - strain relation. Moreover, in the authors' knowledge this kind of approach is quite novel, and in the computational mechanics domain applied to fibre reinforced cementicious matrices, only meso-level models using lattice 
structures have adopted a similar philosophy, e.g. [17-19]. More recently several approaches based upon the partition of unit method have arisen [2022 ]. Within these works, fibres are treated as discrete and are embedded in a quasi-brittle matrix. However, although fibres are discrete entities in [20, 21], they are not discretised into the finite element mesh regarding the composite matrix. Within these models, instead of fibres being explicitly modelled, the reaction forces from the fibre to the matrix are applied to the background mesh at their end points. On the other hand, in the present work, the fibres are explicitly modelled. In [22] a finite element model of an FRC unit cell is developed in which the interface transition zones (ITZ) and the aggregates were homogenised. This approach was only used for evaluating the elastic properties of FRC.

In conclusion, the present approach treats FRC as a two phase material, in which the fibres are explicitly modelled within a three-dimensional background mesh (aggregates/paste). In order to avoid remeshing the volume finite elements for accommodating the random fibre structure, fibres are modelled as embedded cables. The common embedded cable formulation is only able to model the bond-slip behaviour of fibres and does not take into account the dowel effect, which occurs in inclined fibres crossing an active crack. For this purpose, the embedded cable formulation is extended in order to include two shear components. The post-cracking behaviour of the FRC is modelled having into account the fracture energy released by the matrix and the bond-slip behaviour of the fibre/matrix interface.

\section{Numerical approach}

\subsection{Concrete material model}

The nonlinear behaviour of the concrete matrix is modelled with a fixed smeared crack model. This formulation only envisages one crack per integration point and is a particular case of the fixed multi-directional smeared crack model formulation [23-25]. The extension of this formulation for the multiple crack case can be found elsewhere [26, 27]. Since a nonlinear material model to simulate the crack propagation in concrete is adopted, an incremental-iterative procedure is used to solve the resulting system of nonlinear equations. The relationship between the incremental strain and stress is given by the well-known equation:

$$
\Delta \underline{\sigma}=\underline{D} \Delta \underline{\varepsilon}
$$


where $\Delta \underline{\sigma}$ and $\Delta \underline{\varepsilon}$ are, respectively, the stress and strain increment vectors and $\underline{D}$ is the tangent constitutive matrix.

In the adopted smeared crack model, the incremental strain vector is decomposed into an incremental crack strain vector, $\Delta \underline{\varepsilon}^{c r}$, and an incremental strain vector regarding the contribution of the uncracked concrete, i.e. concrete between cracks, $\Delta \underline{\varepsilon}^{c o}$ :

$$
\Delta \underline{\varepsilon}=\Delta \underline{\varepsilon}^{c r}+\Delta \underline{\varepsilon}^{c o}
$$

The strain decomposition in Eq. 2 is the main basic assumption of the smeared crack models and has been widely adopted by several researchers [23-28].

\subsubsection{Crack strain and stress vectors}

Fig. 1(a) shows a sketch of a crack plane within a solid finite element for the three-dimensional case. According to the classical fracture mechanics, three distinct types of crack modes can be considered (Fig. 1(b)). The crack opening mode, Mode I, the in-plane shear mode, Mode II, and the out-ofplane shear mode, Mode III [29, 30]. Note that, for the three-dimensional case, the distinction between Mode II and III can be disregarded [29, 30], see also Fig. 1(b). The referred fracture modes are correlated to the relative displacements between the crack surfaces: Mode I with the crack opening displacement, $w$, and Modes II and III with the crack sliding displacements, respectively, $s_{1}$ and $s_{2}$. The axes of the crack's local coordinate system are defined by the crack normal direction, $\hat{n}$, and both crack tangential directions, $\hat{t}_{1}$ and $\hat{t}_{2}$, see Fig. $1(\mathrm{a})$.

In the smeared crack approach, $w$ is replaced with a crack normal strain, $\varepsilon_{n}^{c r}$, and both $s_{1}$ and $s_{2}$ slide components are replaced, respectively, with the crack shear strain $\gamma_{t 1}^{c r}$ and $\gamma_{t 2}^{c r}$. Thus, the incremental local crack strain vector, $\Delta \underline{\varepsilon}_{l}^{c r}$, has the following components:

$$
\Delta \underline{\varepsilon}_{l}^{c r}=\left[\Delta \varepsilon_{n}^{c r}, \Delta \gamma_{t 1}^{c r}, \Delta \gamma_{t 2}^{c r}\right]^{T}
$$

whereas the components of the incremental crack strain vector in the global coordinate system is defined by:

$$
\Delta \underline{\varepsilon}^{c r}=\left[\Delta \varepsilon_{1}^{c r}, \Delta \varepsilon_{2}^{c r}, \Delta \varepsilon_{3}^{c r}, \Delta \gamma_{23}^{c r}, \Delta \gamma_{31}^{c r}, \Delta \gamma_{12}^{c r}\right]^{T}
$$


with,

$$
\Delta \underline{\varepsilon}^{c r}=\left[\underline{T}^{c r}\right]^{T} \Delta \underline{\varepsilon}_{l}^{c r}
$$

in which $\underline{T}^{c r}$ is the transformation matrix [27].

The incremental stress vector in the local coordinate system, $\Delta \underline{\sigma}_{l}^{c r}$, has the following components:

$$
\Delta \underline{\sigma}_{l}^{c r}=\left[\Delta \sigma_{n}^{c r}, \Delta \tau_{t 1}^{c r}, \Delta \tau_{t 2}^{c r}\right]^{T}
$$

where $\Delta \sigma_{n}^{c r}$ is the incremental crack normal stress, and $\Delta \tau_{t 1}^{c r}$ and $\Delta \tau_{t 2}^{c r}$ are the incremental crack shear stresses, respectively, in $\hat{t}_{1}$ and $\hat{t}_{2}$ directions.

\subsubsection{Concrete constitutive law}

An isotropic linear elastic behaviour is assumed for concrete between cracks, i.e. uncracked or undamaged concrete. Thus, the constitutive relation between $\Delta \underline{\varepsilon}^{c o}$ and $\Delta \underline{\sigma}$ is as follows:

$$
\Delta \underline{\sigma}=\underline{D}^{c o} \Delta \underline{\varepsilon}^{c o}
$$

where $\underline{D}^{c o}$ is the well-known elastic constitutive matrix of the uncracked concrete [31].

In similarity to Eq. 7, the crack opening and shear sliding behaviour can be established in terms of a relationship between $\Delta \underline{\sigma}_{l}^{c r}$ and $\Delta \underline{\varepsilon}_{l}^{c r}$ :

$$
\Delta \underline{\sigma}_{l}^{c r}=\underline{D}^{c r} \Delta \underline{\varepsilon}_{l}^{c r}
$$

where $\underline{D}^{c r}$ is the crack constitutive matrix comprising Modes I, II and III crack fracture parameters. Combining Eqs. 1 to 8, the constitutive law of the cracked concrete is obtained [26, 28]:

$$
\Delta \underline{\sigma}=\underline{D}^{\text {crco }} \Delta \underline{\varepsilon}
$$

$$
\underline{D}^{c r c o}=\underline{D}^{c o}-\underline{D}^{c o}\left[\underline{T}^{c r}\right]^{T}\left(\underline{D}^{c r}+\underline{T}^{c r} \underline{D}^{c o}\left[\underline{T}^{c r}\right]^{T}\right)^{-1} \underline{T}^{c r} \underline{D}^{c o}
$$


where $\underline{D}^{\text {crco }}$ is the constitutive matrix of the cracked concrete.

The $\underline{D}^{c r}$ matrix of the present model does not account for the shearnormal stress coupling effect, therefore this matrix is diagonal with the nonnull terms being the crack's stiffness modulus associated to each fracture mode (Mode I, II and III). The crack opening mode is simulated by an exponential tensile-softening diagram proposed by Cornelissen et al. [32] defined by:

$$
\frac{\sigma_{n}^{c r}\left(\varepsilon_{n}^{c r}\right)}{f_{c t}}=\left\{\begin{array}{cl}
\left(1+\left(c_{1} \frac{\varepsilon_{n}^{c r}}{\varepsilon_{n, u l t}^{c r}}\right)^{3}\right) \exp \left(-c_{2} \frac{\varepsilon_{n}^{c r}}{\varepsilon_{n, u l t}^{c r}}\right)- & \\
\frac{\varepsilon_{n}^{c r}}{\varepsilon_{n, u l t}^{c r}}\left(1+c_{1}^{3}\right) \exp \left(-c_{2}\right) & \text { if } 0<\varepsilon_{n}^{c r}<\varepsilon_{n, u l t}^{c r} \\
0 & \text { if } \varepsilon_{n}^{c r} \geq \varepsilon_{n, u l t}^{c r}
\end{array}\right.
$$

where $c_{1}=3.0$ and $c_{2}=6.93$, for plain concrete. The ultimate crack normal strain, $\varepsilon_{n, u l t}^{c r}$, is computed from:

$$
\varepsilon_{n, u l t}^{c r}=\frac{1}{k} \cdot \frac{G_{f}}{f_{c t} l_{b}}
$$

where $f_{c t}, G_{f}$ and $l_{b}$ are the tensile strength, fracture energy and crack band width, respectively, whereas $k$ is a constant computed from:

$$
\begin{aligned}
k=\left[\frac{1}{c_{2}}\left[1+6\left(\frac{c_{1}}{c_{2}}\right)^{3}\right]\right. & -\left[\frac{1}{c_{2}}+\right. \\
& \left.\left.c_{1}^{3}\left(\frac{1}{c_{2}}+\frac{3}{c_{2}^{2}}+\frac{6}{c_{2}^{3}}+\frac{6}{c_{2}^{4}}\right)+\frac{1}{2}\left(1+c_{1}^{3}\right)\right]\right] \exp \left(-c_{2}\right)
\end{aligned}
$$

The Mode I stiffness modulus, $D_{n}^{c r}$, comprised in the $\underline{D}^{c r}$ matrix is determined with: 


$$
\begin{aligned}
D_{n}^{c r}=f_{c t} & {\left[3\left(c_{1} \frac{\varepsilon_{n}^{c r}}{\varepsilon_{n, u l t}^{c r}}\right)^{2} \frac{c_{1}}{\varepsilon_{n, u l t}^{c r}} \exp \left(-c_{2} \frac{\varepsilon_{n}^{c r}}{\varepsilon_{n, u l t}^{c r}}\right)+\right.} \\
& \left.\exp \left(-c_{2} \frac{\varepsilon_{n}^{c r}}{\varepsilon_{n, u l t}^{c r}}\right)\left(-c_{2} \frac{\varepsilon_{n}^{c r}}{\varepsilon_{n, u l t}^{c r}}\right)\left[1+\left(c_{1} \frac{\varepsilon_{n}^{c r}}{\varepsilon_{n, u l t}^{c r}}\right)^{3}\right]-\frac{1+c_{1}^{3}}{\varepsilon_{n, u l t}^{c r}} \exp \left(-c_{2}\right)\right]
\end{aligned}
$$

The shear fracture modes II and III stiffness modulus, respectively, $D_{t 1}^{c r}$ and $D_{t 2}^{c r}$, are computed from:

$$
D_{t 1}^{c r}=D_{t 2}^{c r}=\frac{\beta}{1-\beta} G_{c}
$$

where $G_{c}$ and $\beta$ are, respectively, the elastic shear modulus and the shear retention factor. A linear softening constitutive law is used to model the shear degradation of the concrete with the increase of the crack normal strain:

$$
\beta=1-\frac{\varepsilon_{n}^{c r}}{\varepsilon_{n, u l t}^{c r}}
$$

\subsection{Fibre structure modelling}

In the present approach, the fibre structure that represents, with a certain level of accuracy, the distribution of fibres in a hardened matrix is randomly generated by a Monte Carlo procedure. The algorithm to generate the fibres' positioning and orientation as well as its performance can be found elsewhere [10]. After the generation of the element mesh representing the fibres, there is the need to insert this "fibre mesh" into the solid three-dimensional mesh that models the plain concrete.

In the present work, since it is assumed that the embedded elements (representing the fibres) are always straight, it is enough to represent the fibre by two end-nodes defined in the global coordinate system. It should be noted, however, that a fibre can intersect one or even several solid elements, thus there is the need to allow for several additional points for the distinct intersection points. Therefore, a fibre can be represented by several embedded elements, in which each element contributes exclusively to the reinforcement 
of a single solid element (brick). The determination of the coordinates of these intersecting points was performed by an inverse mapping technique. The search of the intersecting points was carried out at the embedded element's natural axis.

\subsubsection{Inverse mapping technique}

The inverse mapping technique basically consists in looking within the solid element's natural coordinate domain $(\xi, \eta, \varsigma)$, correspondent to the solid global coordinates, $\left(x_{1}^{c}, x_{2}^{c}, x_{3}^{c}\right)$, which match the embedded element's global coordinates, i.e $\left(x_{1}^{f}, x_{2}^{f}, x_{3}^{f}\right) \equiv\left(x_{1}^{c}, x_{2}^{c}, x_{3}^{c}\right)$, see Fig. 2 .

$$
\left[\begin{array}{c}
\sum_{i=1}^{n_{f}} N_{i}^{f}(\zeta) x_{1, i}^{f} \\
\sum_{i=1}^{n_{f}} N_{i}^{f}(\zeta) x_{2, i}^{f} \\
\sum_{i=1}^{n_{f}} N_{i}^{f}(\zeta) x_{3, i}^{f}
\end{array}\right]-\left[\begin{array}{c}
\sum_{i=1}^{n_{c}} N_{i}^{c}(\xi, \eta, \varsigma) x_{1, i}^{c} \\
\sum_{i=1}^{n_{c}} N_{i}^{c}(\xi, \eta, \varsigma) x_{2, i}^{c} \\
\sum_{i=1}^{n_{c}} N_{i}^{c}(\xi, \eta, \varsigma) x_{3, i}^{c}
\end{array}\right]=0
$$

In order to obtain the embedded element's point $P\left(x_{1, p}, x_{2, p}, x_{3, p}\right)$ that intersects the solid element, Eq. 17 is solved by the Newton-Raphson method. Whenever this method fails to converge the bisection method is used. Therefore, for each embedded element, a search is performed within the natural coordinate system $(\zeta)$. The embedded element's point $\zeta_{p}$, which intercepts, skirts or touches one of the solid element's faces (Fig. 2), must comply with one of the following conditions:

$$
\begin{aligned}
& \left\|\xi^{f}\right\|=1 \wedge\left\|\eta^{f}\right\| \leq 1 \wedge\left\|\varsigma^{f}\right\| \leq 1 \\
& \left\|\xi^{f}\right\| \leq 1 \wedge\left\|\eta^{f}\right\|=1 \wedge\left\|\varsigma^{f}\right\| \leq 1 \\
& \left\|\xi^{f}\right\| \leq 1 \wedge\left\|\eta^{f}\right\| \leq 1 \wedge\left\|\varsigma^{f}\right\|=1
\end{aligned}
$$

where $\xi^{f}, \eta^{f}$ and $\varsigma^{f}$ are the embedded element's natural coordinates within the solid element's natural coordinate system.

After the completion of the point $P$ determination, the embedded elements' mesh data is rewritten in order to take into account the compatibility between the embedded fibres and the solid mesh elements. Coincident nodes 

Computers \& Structures, Vols. 94-95, 22-33

from different solid element faces belonging to the same embedded element are merged, and finally the embedded elements' nodes are renumbered.

\subsubsection{Constitutive model for the embedded fibres}

As already mentioned, the present formulation of the embedded fibre model does not take into account fibre bond - slip behaviour in a direct fashion. Therefore, the embedded element is modelled with a perfectly bonded assumption. In fact, the bond - slip behaviour is simulated in an indirect fashion from the transformation of a load - slip relationship, $P-s$, to a tensile stress - strain relation, $\sigma_{f}-\varepsilon_{f}$.

The constitutive laws for the embedded fibres were determined from fibre pullout tests carried out in the scope of the present research project [10]. Three distinct $\sigma_{f}-\varepsilon_{f}$ laws corresponding, respectively, to the pullout inclination angles of the studied fibres, $\alpha,\left(0^{\circ}, 30^{\circ}\right.$ and $\left.60^{\circ}\right)$ were ascertained [10]. Fig. 3 depicts the procedure adopted to obtain the $\sigma_{f}-\varepsilon_{f}$ relationship, where $\varepsilon_{f}, l_{b}$ and $s$ are, respectively, the embedded fibre strain, the crack band width and the steel fibre's slip; $\sigma_{f}$ is the ratio between the pullout force, $P$, and the fibre's cross-sectional area, $A_{f}$.

The trilinear $\sigma_{f}-\varepsilon_{f}$ diagram used to model the fibres including the bond - slip effect was obtained by fitting the experimental pullout load-slip curves. For each fibre inclination angle, $\alpha$, an average pullout load-slip curve was computed from the experimental envelope of the series with an embedded length of $10 \mathrm{~mm}$ and $20 \mathrm{~mm}$, thus corresponding, approximately, to the expected pullout load-slip behaviour of a fibre with an embedded length of $15 \mathrm{~mm}$. This averaging procedure was adopted for two reasons. The influence of the fibre embedded length on the pullout behaviour is not so significant as the fibre inclination effect, and its influence is almost linear [10]. In addition, the theoretical average value of the embedded length of a fibre crossing an active crack is $l_{f} / 4=15 \mathrm{~mm}$ [33], where $l_{f}$ is the fibre length (end-to-end). This simplification has a rational and scientific basis. Additionally, in the developed model only the most relevant data obtained from fibre pullout tests is included in the model, thus optimising the computation time.

The tensile stress - strain law assigned to an embedded fibre depends on the inclination angle, $\theta$, between the fibre and the vector normal to the active crack surface, see Fig. 4 . Moreover, the $\sigma_{f}-\varepsilon_{f}$ also depends on the crack band width, $l_{b}$, of the intersected solid element, see Fig. 3. Due to the impossibility of having a $\sigma_{f}-\varepsilon_{f}$ law for every possible inclination angle and embedded length, the $\sigma_{f}-\varepsilon_{f}$ laws obtained from the pullout tests with an 
with,

angle, $\alpha$, of $0^{\circ}, 30^{\circ}$ and $60^{\circ}$ were assigned to the embedded fibres with an orientation towards the active crack surface $\theta$ ranging from, respectively, $\left[0^{\circ}\right.$, $15^{\circ}\left[,\left[15^{\circ}, 45^{\circ}\right.\right.$ and $\left[45^{\circ}, 75^{\circ}\right.$. The contribution of the fibres with $\theta$ in the interval $\left[75^{\circ}, 90^{\circ}\right]$ was neglected.

2.2.3. Evaluation of the stiffness matrix of the concrete and embedded fibre structure

The element stiffness matrix representing a concrete bulk reinforced with fibres can be expressed as:

$$
\underline{K}^{r c}=\underline{K}^{c r c o}+\sum_{i=1}^{n_{f}} \underline{K}_{i}^{f}
$$

where $\underline{K}^{\text {crco }}, \underline{K}_{i}^{f}$ and $n_{f}$ are, respectively, the concrete element stiffness matrix, the stiffness matrix of the $i^{\text {th }}$ fibre that is embodied into the concrete mother-element, and the total number of embodied fibres in the concrete element. The concrete element stiffness matrix is given by:

$$
\underline{K}^{c r c o}=\int_{V} \underline{B}^{T} \underline{D}^{c r c o} \underline{B} d V
$$

where $\underline{D}^{\text {crco }}$ is the cracked concrete's constitutive matrix (determined from Eq. 10) and $\underline{B}$ is the well-known strain - displacement matrix of a solid element [31].

The axial contribution of the fibre reinforcement to the stiffness matrix can be computed by the internal work regarding the axial component as follows:

$$
\begin{aligned}
W_{a} & =\int_{V} \delta \varepsilon_{f}^{T} \sigma_{f} d V \\
& =\int_{L} \delta \varepsilon_{f}^{T} E_{f} \varepsilon_{f} A_{f} d L
\end{aligned}
$$


where $\sigma_{f}, \varepsilon_{f}$ and $A_{f}$ are the stress, the strain and the cross-sectional area of the fibre, whereas $J$ is the Jacobian at the sampling point of the integration scheme adopted in the numerical evaluation of the $\underline{K}_{i}^{f}$. Thus, substituting Eq. 22 in Eq. 21, the internal work can be computed in natural coordinates by:

$$
W_{a}=\int_{-1}^{+1} \delta \varepsilon_{f}^{T} E_{f} \varepsilon_{f} A_{f} J d s
$$

The stiffness matrix is obtained by substituting $\varepsilon_{f}=\underline{T}_{1}^{f} \underline{B} \underline{d}$ in Eq. 23, where $\underline{d}$ is the vector with the solid element's nodal displacements and $\underline{T}_{1}^{f}$ is the vector corresponding to the first line of the transformation matrix from the fibre's local coordinate system to the global coordinate system, $\underline{T}^{f}$, given by:

$$
\begin{aligned}
& \underline{T}^{f}=\left[\begin{array}{ccccc}
a_{11}^{2} & a_{12}^{2} & a_{13}^{2} & a_{12} a_{13} & \\
a_{21} a_{31} & a_{22} a_{32} & a_{23} a_{33} & 0.5\left(a_{22} a_{33}+a_{23} a_{32}\right) & \ldots \\
a_{11} a_{31} & a_{12} a_{32} & a_{13} a_{33} & 0.5\left(a_{13} a_{32}+a_{12} a_{33}\right) &
\end{array}\right. \\
& \left.\begin{array}{ccc} 
& a_{11} a_{13} & a_{11} a_{12} \\
\cdots & 0.5\left(a_{23} a_{31}+a_{21} a_{33}\right) & 0.5\left(a_{21} a_{32}+a_{12} a_{31}\right) \\
& 0.5\left(a_{13} a_{31}+a_{11} a_{33}\right) & 0.5\left(a_{12} a_{31}+a_{11} a_{32}\right)
\end{array}\right]
\end{aligned}
$$

where $a_{i j}$ are the components of the matrix $\underline{a}$ comprising the direction cosines, i.e. the projection of the fibre's local coordinate system $\left(x_{1}^{\prime}, x_{2}^{\prime}, x_{3}^{\prime}\right)$ versors towards the global coordinate system $\left(x_{1}, x_{2}, x_{3}\right)$ versors (see Fig. 4 ):

$$
\underline{a}^{f}=\left[\begin{array}{lll}
a_{11} & a_{12} & a_{13} \\
a_{21} & a_{22} & a_{23} \\
a_{31} & a_{32} & a_{33}
\end{array}\right]=\left[\begin{array}{ccc}
\cos \left(x_{1}^{\prime}, x_{1}\right) & \cos \left(x_{1}^{\prime}, x_{2}\right) & \cos \left(x_{1}^{\prime}, x_{3}\right) \\
\cos \left(x_{2}^{\prime}, x_{1}\right) & \cos \left(x_{2}^{\prime}, x_{2}\right) & \cos \left(x_{2}^{\prime}, x_{3}\right) \\
\cos \left(x_{3}^{\prime}, x_{3}\right) & \cos \left(x_{3}^{\prime}, x_{2}\right) & \cos \left(x_{3}^{\prime}, x_{3}\right)
\end{array}\right]
$$

Hence, the component of the stiffness matrix with the fibre's axial contribution is given by:

$$
\underline{K}_{a}^{f}=\int_{-1}^{1} \underline{B}^{T}\left[\underline{T}_{1}^{f}\right]^{T} \underline{T}_{1}^{f} \underline{B} E_{f} A_{f} J d s
$$

\footnotetext{
In a similar way, the components of the fibre stiffness matrix with the shear contribution is given by:
} 


$$
\begin{aligned}
& \underline{K}_{s, 1}^{f}=\int_{-1}^{1} \underline{B}^{T}\left[\underline{T}_{2}^{f}\right]^{T} \underline{T}_{2}^{f} \underline{B} G \bar{A}_{f} J d s \\
& \underline{K}_{s, 2}^{f}=\int_{-1}^{1} \underline{B}^{T}\left[\underline{T}_{3}^{f}\right]^{T} \underline{T}_{3}^{f} \underline{B} G \bar{A}_{f} J d s
\end{aligned}
$$

where $G$ is the fibre's elastic shear modulus, and $\underline{T}_{2}^{f}$ and $\underline{T}_{3}^{f}$ are, respectively, the vector corresponding to the second and third lines of the transformation matrix, see Eq. 24. For the shear components, the value adopted for $\bar{A}_{f}$ is the reduced shear area for circular sections [34].

The equivalent nodal forces vector, $\underline{q}^{e}$, is computed from:

$$
\underline{q}^{e}=\underbrace{\int_{V} \underline{B}^{T} \underline{\sigma} d V}_{\text {concrete }}+\underbrace{\int_{\text {axial component }}^{1} \underline{B}^{T} \underline{T}^{T} \sigma_{f} A_{f} J d s}_{\text {fibre contribution }}+\underbrace{\int_{-1}^{1} \underline{B}^{T} \underline{T}^{T} \underline{\tau}_{f} \bar{A}_{f} J d s}_{\text {shear components }}
$$

where $\sigma_{f}$ is the fibre stress with axial component obtained from the adopted tensile stress - strain diagram for modelling the fibre pullout behaviour. On the other hand, $\underline{\tau}_{f}$ is the fibre's stress vector with the two shear components. For the fibre shear behaviour an elasto-plastic behaviour was adopted. A shear stress cut-off was introduced for shear strains higher than 0.01. Moreover, the fibre's shear contribution was only taken into account for crack opening width, $w$, smaller than $0.5 \mathrm{~mm}\left(w=\varepsilon_{n}^{c r} l_{b}\right)$. The shear stress yield criterion used in the present work is assumed to be independent from the axial stress.

\section{Numerical simulations}

The model performance is appraised by simulating uniaxial tensile tests and three-point bending tests carried out with self-compacting concrete specimens reinforced with 30 and $45 \mathrm{~kg} / \mathrm{m}^{3}$ steel fibres, designated as Cf30 and Cf45 series, respectively. Details about the tests set-up and specimens geometry can be found elsewhere $[10,35,36]$. The experimental results obtained in both uniaxial and bending tests for the studied fibre contents were modelled with two numerical curves. These numerical curves were attained by 
running under the FEM basis two distinct "virtual" fibre structures obtained from the procedure described in section 2.2. The two numerical simulations obtained per series were distinguished and designated, respectively, as curve A and B. Although curves A and B have distinct fibre structures, within each series/specimens both have exactly the same volumetric fibre content and, consequently, the same total number of fibres within the specimen's volume. However, note that the arrangement of the fibres within the concrete mesh is distinct for curves A and B. Due to the randomness implicit to the developed approach there is the possibility of obtaining an envelope of numerical responses, i.e. with a certain scatter associated to distinct fibre structures, as a consequence of distinct number of fibres crossing an active crack and with distinct inclination angles.

Table 3 includes both the number of fibres that intersect the active crack surface and the correspondent orientation factor, $\eta$, regarding both curves A and $\mathrm{B}$ for each test and series modelled. Note that the orientation factor of the fibres crossing the crack surface was computed as:.

$$
\eta=\sum_{i=1}^{N_{f}} \cos \left(\theta_{i}\right) / N_{f}
$$

where $N_{f}$ is the total number of fibres that intersect the crack plane and $\cos \left(\theta_{i}\right)$ is the scalar product of the $i^{\text {th }}$ fibre versor (which also intersects the crack plane) and the versor normal to the crack plane, and $\theta_{i}$ is the out-plane angle.

\subsection{Uniaxial tensile tests}

Fig. 5(a) represents the mesh used exclusively for the concrete matrix phase, whereas Figs. 5(b) and 5(c) depict three-dimensional meshes used for modelling the steel fibre contribution, for the Cf30 and Cf45 series, respectively. Note that the fibres intersected by the notch were not included into the finite element mesh. Moreover, since the numerical fibre mesh was obtained for a cylinder with $300 \mathrm{~mm}$ of height, and on the other hand the tested cylinder had a height of only $150 \mathrm{~mm}$, the fibres that are not fully contained in only one half of the specimen were also removed. These simplifications have almost no influence on the numerical simulations, since the fibre contribution outside the fracture zone is very reduced for the tensile behaviour of this type of specimen. 

Computers \& Structures, Vols. 94-95, 22-33

In the present mesh Lagrangian 8-node solid elements are used for modelling the plain concrete contribution. Since the specimen has a notch at its mid-height, all the nonlinear behaviour is localised at the notch region, thus a $2 \times 2 \times 1$ Gauss-Legendre integration scheme is used (1 integration point in the loading direction). The remaining solid elements are modelled with linear elastic behaviour, and a $2 \times 2 \times 2$ Gauss-Legendre integration scheme is adopted. The Cornelissen et al. [32] softening law was used for modelling the post-cracking nonlinear behaviour of SCC. The material properties of the concrete matrix used in the simulations are included in Table 1. These values were obtained by taking into account the strength class [37] registered for the Cf30 and Cf45 series. On the other hand, the steel fibres are modelled with 3D embedded elements with two integration points (GaussLegendre). Nonlinear behaviour is ascribed to all the embedded elements. Nevertheless, only the embedded elements belonging to a "mother" element (brick) with nonlinear behaviour, i.e. cracking, develop nonlinear behaviour, i.e. fibre pullout. The other embedded elements remain in the elastic phase. Table 2 includes the parameters of the tri-linear $\sigma_{f}-\varepsilon_{f}$ laws ascribed to the embedded elements.

Figs. 6 and 7 depict the numerical simulations of the uniaxial tensile tests of the Cf30 and Cf45 series, respectively. A good agreement with the experimental responses was obtained for both series. The predicted numerical tensile strength is near the upper bound limit of the experimental envelope. This is feasible, because during testing it is almost impossible to completely exclude eccentricities, thus a slight misalignment of the specimen with the loading axis will introduce a bending moment. Due to this moment, the experimental tensile strength is smaller than the correspondent numerical one. Moreover, the maximum tensile stress obtained in the numerical simulations, i.e. maximum load divided per fractured area, is smaller than the value of the tensile strength used in the local material law for concrete (see Table 1). This is due to the stress concentrations that arise at the notch tip. Thus, when the concrete's tensile strength is attained near the notch tip, for the maximum load capacity of the specimen, the overall tensile stress computed from averaging the tensile load with the net cross section at the notch will be smaller than the concrete's tensile strength defined as a material property.

After the coalescence of micro-cracking into a macro-crack, the tensile stress drops abruptly to a crack opening width varying from, approximately, 0.08 to $0.16 \mathrm{~mm}$. Above this crack width level, the reinforcement mechanisms of the hooked steel fibres start to be mobilised, enabling a slight hardening 
of the tensile response. Figs. 8(a) and 8(b) show the fibres intersecting the crack plane regarding the fibre structures used to obtain the numerical curve A for the Cf30 and Cf45 series, respectively. Figs. 8(c) and 8(d) depict the normal stresses at the crack plane for a crack opening width of $0.16 \mathrm{~mm}$ for the curve A of the Cf30 and Cf45 series, respectively. Due to the higher number of fibres intersecting the crack plane a higher stress transfer level for the Cf45 series is clearly visible, which is translated into an overall tensile stress of nearly $1.2 \mathrm{MPa}$ in opposition to the $0.8 \mathrm{MPa}$ observed for the Cf30 series (see curves A in Figs. 6 and 7).

The differences observed in the residual tensile strengths between the Cf30 and Cf45 series are more considerable for higher crack opening widths, mainly for $w>1 \mathrm{~mm}$ (Figs. 6 and 7). These differences in the post-cracking behaviour are not just ascribed to the higher number of fibres intersecting the crack plane in the Cf45 series, as a direct consequence of the higher volumetric fibre content. The full explanation and discussion of this phenomenon is out of the scope of the present work and can be found elsewhere [10]. Nevertheless, and very briefly, it can be pointed out that those differences in the post-cracking behaviour can be ascribed to distinct micro-mechanical behaviours of the fibres in the Cf30 and C45 series. For the Cf45 series, fibre rupture did not occur so often due to both a less resistant matrix and the reduction of the average fibre orientation angle towards the crack plane [10]. Figs. 8(e) and 8(f) depict the normal stresses at the crack plane for a crack opening width of $2 \mathrm{~mm}$ for the Cf30 and Cf45 series, respectively. The differences in the grade of the residual crack stresses between Cf30 and Cf45 is quite notorious.

\subsection{Three-point bending tests}

The sketch of the finite element mesh used to model the concrete matrix phase in the prismatic specimens for both Cf30 and Cf45 series is included in Fig. 9(a). On the other hand, Fig. 9(b) provides a three-dimensional view of one mesh used to model the steel fibre phase contribution for the Cf30 series. The steel fibre mesh for the Cf45 series is not represented here since its graphical rendering would not enable a clear visualisation. The fibres intersected by the notch were removed, as was performed for the tensile test simulations.

Lagrangian 8-node solid elements are also used to model the concrete behaviour in the prismatic specimen. In similarity to what was carried out for modelling the tensile tests, all the nonlinear behaviour was localised at 
the notch region (at mid-span of the beam). Thus, a $2 \times 1 \times 2$ Gauss-Legendre integration scheme is used ( 1 integration point in the normal direction to the crack surface, i.e. in the longitudinal axis of the prism). The remaining solid elements are assumed to have a linear elastic behaviour, and a $2 \times 2 \times 2$ Gauss-Legendre integration scheme is adopted. The Cornelissen et al. [32] softening law was used to simulate the SCC fracture mode I propagation. The values of the material properties of the concrete used in the current simulations are the same already adopted in the simulations of the uniaxial tensile tests, see Table 1. The steel fibres are modelled with 3D embedded elements with two Gauss-Legendre integration points. Only the embedded elements, which intersect a crack at the integration point of the solid element, develop nonlinear behaviour.

The numerical simulations of the three-point bending tests are included in Figs. 10(a) and 10(b) for the Cf30 and Cf45 series, respectively. The agreement between the numerical curve and the experimental results was quite good for both series.

Regarding the Cf30 series, the load at crack initiation obtained in the numerical simulation was modelled with accuracy. However, for the numerical curve B a significant load decay is observed down to the lower bound, L.B., of the envelope of the experimental results. Up to a deflection of nearly $0.75 \mathrm{~mm}$, the numerical curve $\mathrm{B}$ arises just below the L.B. of the experimental envelope. After the later deflection, the curve is within the experimental envelope. On the other hand, the numerical curve A (with a higher number of fibres intersecting the crack plane, see Table 3) was always within the experimental envelope, thus the aforementioned decay was not observed. The agreement between the numerical curves of the Cf45 series and the experimental results was also high. Moreover, the abovementioned load decay was also not observed for neither of the numerical simulations of the Cf45 series.

\section{Conclusions}

In this work a numerical approach to model the behaviour of steel fibre reinforced concrete, SFRC, was presented based upon the micro-mechanical behaviour of the steel fibres. The adopted strategy comprises three main steps: i) assessing the fibre pullout behaviour (micro-level); ii) generation of "virtual" fibre structures (meso-level); and iii) modelling the SFRSCC as a two phase material, in which the concrete phase is modelled with a smeared crack model, while the positioning and orientation of the fibres correspond to 
the fibre phase and are obtained from step ii. Finally, the fibre reinforcement mechanisms are modelled with the micro-mechanical behaviour laws obtained in step i.

The numerical finite element simulations of both the uniaxial tensile tests and three-point bending tests revealed a very good agreement with the experimental test results. Having a realistic approximation of the actual fibre distribution and with the knowledge of the micro-mechanical behaviour of the fibres, it is possible to predict the macro-mechanical behaviour of SFRC specimens. Moreover, since for the generation of the "virtual" fibre structures a Monte-Carlo procedure was adopted due to the randomness implicit to this approach there is the possibility of obtaining an envelope of numerical responses. The scatter of the numerical simulations is ascribed to the distinct fibre structures as a consequence of a different number of fibres crossing an active crack and with distinct inclination angles, which will be mobilised in distinct levels, thus contributing in different ways to the overall mechanical behaviour. This approach was only used for modelling notched specimens, i.e. where the fracture plane is previously known. In a future stage, further numerical research should be extended to specimens with other geometries and loading conditions.

\section{Acknowledgements}

The authors of the present work wish to acknowledge the support provided by ADI "FEDER - Programa Operacional Factores de Competetividade" research project QREN, N. 5387, LEGOUSE.

\section{References}

[1] K. Visalvanich, A. E. Naaman, Fracture model for fiber reinforced concrete, ACI J. 80 (2) (1983) 128-138.

[2] V. C. Li, Y. Wang, S. Baker, A micromechanical model of tension softening and bridging toughning of short random fiber reinforced britle matrix composites, J. Mech. Phys. Solids 39 (5) (1991) 607-625.

[3] V. C. Li, Postcrack scaling relations for fiber reinforced cementicious composites, ASCE J. Mater. Civil Eng. 4 (1) (1992) 41-57. 
[4] M. Maalej, V. C. Li, T. Hashida, Effect of fiber rupture on tensile properties of short fiber composites, J. Eng. Mech.-ASCE 121 (8) (1995) 903-913.

[5] P. Stroeven, Stereology of concrete reinforced with short steel fibres, Fract. Mech. Struct. Aspects Concr. 31 (1986) 15-28.

[6] RILEM TC 162-TDF, Test and design methods for steel fibre reinforced concrete - design of steel fibre reinforced concrete using the $\sigma$-w method: principles and application, Mater. Struct. 35 (249) (2002) 262-276.

[7] S. Grünewald, J. C. Walraven, Self-compacting fibre reinforced concrete - orientation effect of steel fibres in large beams, in: Workshop - Design rules for steel fibre reinforced concrete structures, Oslo, Norway, 2003, pp. 107-113.

[8] P. Stähli, R. Custer, J. van Mier, On flow properties, fibre distribution, fibre orientation and flexural behaviour of FRC, Mater. Struct. 41 (1) (2008) 189-196.

[9] L. Vandewalle, G. Heirman, F. Van Rickstal, Fibre orientation in selfcomapcting fibre reinforced concrete, in: R. Gettu (Ed.), Sevnth. Intnl. RILEM Symposium on Fibre Reinforced Concrete: Design and Applications, Chennai, India, 2008, pp. 719-728.

[10] V. M. C. F. Cunha, Steel fibre reinforced self-compacting concrete - from micromechanics to composite behaviour, Ph.D. thesis, Dep. Civil Engineering, University of Minho, Portugal (2010), (http://hdl.handle.net/1822/10667).

[11] V. M. C. F. Cunha, J. A. O. Barros, J. M. Sena-Cruz, Pullout behaviour of steel fibres in self-compacting concrete, ASCE J. Mater. Civil Eng. 22 (1) (2010) 1-9.

[12] S. Balakrishnan, D. W. Murray, Finite element prediction of reinforced concrete behaviour, Struct. Engrg. Rep. No. 138, University of Alberta, Canada (1986).

[13] T. Y. Chang, H. Taniguchi, W. F. Chen, Non-linear finite element analysis of reinforced concrete panels, J. Struct. Eng.-ASCE 113 (1) (1987) $122-140$. 
[14] A. Elwi, M. Hurdey, Finite element model for curved embedding reinforcement, J. Eng. Mech.-ASCE 115 (4) (1989) 740-757.

[15] P. Bhatt, M. S. Barj, G. F. Elnounu, M. Memon, Non-linear finite element analysis of shearwall-floor slab junction, in: D. R. Owen, E. Hinton (Eds.), Second International Conference on Computational Plasticity, Swansea, Wales, 1989, pp. 1319-1330.

[16] A. Ranjbaran, Mathematical formulation of embedded reinforcements in 3d bricks elements, Communications in Numerical Methods in Engineering 12 (1996) 897-903.

[17] A. Van Hauwaert, J. G. M. Van Mier, Computational modelling of the fibre-matrix bond in steel fibre reinforced concrete, in: H. Mihashi, K. Rokugo (Eds.), Fracture Mechanics of Concrete Structures, Freiburg, Germany, 1998, pp. 561-571.

[18] J. P. B. Leite, V. Slowik, H. Mihashi, Computer simulation of fracture processes of concrete using mesolevel models of lattice structures, Cem. Concr. Res. 34 (6) (2004) 1025-1033.

[19] J. E. Bolander, Numerical modelling of fibre reinforced cement composites: linking material scales, in: M. Prisco, R. Felicetti, G. Plizzari (Eds.), $6^{\text {th }}$ RILEM Symposium on Fibre Reinforced Concretes, Varenna, Italy, 2004, pp. 45-60.

[20] F. Radtke, A. Simone, L. Sluys, A computational model for failure analysis of fibre reinforced concrete with discrete treatment of fibres, Eng. Fract. Mech. 77 (4) (2010) 597-620.

[21] F. Radtke, A. Simone, L. Sluys, A partition of unity finite element method for obtaining elastic properties of continua with embedded thin fibres, Int. J. Numer. Methods Eng. 84 (6) (2010) 708-732.

[22] E. Gal, R. Kryvoruk, Meso-scale analysis of FRC using a two-step homogenization approach, Comput. Struct. 89 (11-12) (2011) 921-929.

[23] Z. Bazant, P. Gambarova, Rough cracks in reinforced concrete, ASCE J. Struct. Div. 106 (4) (1980) 819-842. 
[24] R. de Borst, P. Nauta, Non-orthogonal cracks in smeared finite element model, Eng. Comput. 2 (1985) 35-46.

[25] J. G. Rots, Computational modelling of concrete fracture, Ph.D. thesis, Delft University of Technology, Netherlands (1988).

[26] J. M. Sena-Cruz, Strenghning of concrete structures with near surface mounted CFRP laminate strips, Ph.D. thesis, Dep. Civil Engineering, Universidade do Minho, Portugal (2005) (http://hdl.handle.net/1822/11781).

[27] A. Ventura-Gouveia, J. A. O. Barros, Álvaro Azevedo, J. Sena-Cruz, Multi-fixed smeared 3D crack model to simulate the behaviour of fibre reinforced concrete structures, in: T. Marques et al. (Eds.), CCC $2008-$ Challenges for Civil Construction, FEUP, Porto, 2008, pp. Paper T2-3, $11 \mathrm{pp}$.

[28] J. A. O. Barros, Comportamento do betão reforçado com fibras, análise experimental e simulação numérica, Ph.D. thesis, Faculdade de Engenharia da Universidade do Porto, Portugal (in Portuguese) (1995).

[29] S. P. Shah, S. E. Swartz, C. Ouyang, Fracture mechanics of concrete (application of fracture mechanics to concrete, rock and other quasibritle materials), John Wiley \& Sons, Inc., 1995.

[30] P. Z. Bazant, J. Planas, Fracture and size effect in concrete and other quasibrittle materials, New directions in Civil Engineering, CRC Press, Boca Raton, Florida, 1998.

[31] O. Zienkiewicz, R. Taylor, Finite element method - Vol. 1: The basis, Butterworth-Heinemann, Oxford, England, 2000.

[32] H. A. W. Cornelissen, D. A. Hordijk, H. W. Reinhardt, Experimental determination of crack softening characteristics of normal and lightweight concrete, HERON, Fracture Mechanics and Structural Aspects of Concrete 31 (2) (1986) 45-56.

[33] P. Stroeven, J. Hu, Effectiveness near boundaries of fibre reinforcement in concrete, Mater. Struct. 39 (2006) 1001-1013. 
[34] S. P. Timoshenko, J. N. Goodier, Theory of Elasticity, McGraw-Hill, New York, 1991.

[35] RILEM TC 162-TDF, Test and design methods for steel fibre reinforced concretes: Uni-axial tension test for steel fibre reinforced concrete, Mater. Struct. 34 (1) (2001) 3-6.

[36] RILEM TC 162-TDF, Test and design methods for steel fibre reinforced concrete - bending test (final recommendation), Mater. Struct. 35 (253) (2002) 579-582.

[37] CEB-FIP, CEB-FIP Model Code 1990: Design code, Ceb bulletin d'information no. 190, CEB-FIP Comité Euro-International du Béton, Paris, France (1993). 


\section{List of Tables}

Table 1: Concrete properties used in the simulation.

Table 2: Tri-linear stress - strain diagrams used for modelling the fibres' bond - slip behaviour.

Table 3: Number of fibres and orientation factor at the crack surface of the embedded fibre meshes used for obtaining the distinct numerical curves.

Table 1: Concrete properties used in the simulation.

\begin{tabular}{l|cc}
\hline Property & Cf30 & Series \\
& \multicolumn{2}{|c}{$\rho=2.4 \times 10^{-5} \mathrm{~N} / \mathrm{mm}^{3}$} \\
\hline Density & \multicolumn{2}{c}{$\nu_{c}=0.20$} \\
Poisson's ratio & $41300 \mathrm{~N} / \mathrm{mm}^{2}$ & $40600 \mathrm{~N} / \mathrm{mm}^{2}$ \\
Young's modulus & $71.1 \mathrm{~N} / \mathrm{mm}^{2}$ & $67.2 \mathrm{~N} / \mathrm{mm}^{2}$ \\
Compressive strength & $4.6 \mathrm{~N} / \mathrm{mm}^{2}$ & $4.5 \mathrm{~N} / \mathrm{mm}^{2}$ \\
Tensile strength & $0.117 \mathrm{~N} / \mathrm{mm}^{2}$ & $0.114 \mathrm{~N} / \mathrm{mm}$ \\
Fracture energy & $l_{b}=5 \mathrm{~mm}$ (equal to element height at the notch) \\
Crack band-width
\end{tabular}

Table 2: Tri-linear stress - strain diagrams used for modelling the fibres' bond - slip behaviour (see also Fig. 3)

\begin{tabular}{cccr|cccccc}
\hline $\begin{array}{c}\alpha \\
{[\mathrm{deg}]}\end{array}$ & $\begin{array}{c}\theta \\
{[\mathrm{deg}]}\end{array}$ & Series & $\begin{array}{r}\text { Failure } \\
\text { mode }\end{array}$ & $\begin{array}{c}\sigma_{f, 1} \\
{[\mathrm{MPa}]}\end{array}$ & $\begin{array}{c}\sigma_{f, 2} \\
{[\mathrm{MPa}]}\end{array}$ & $\begin{array}{c}\sigma_{f, 3} \\
{[\mathrm{MPa}]}\end{array}$ & $\begin{array}{c}\varepsilon_{f, 1} \\
{[-]}\end{array}$ & $\begin{array}{c}\varepsilon_{f, 2} \\
{[-]}\end{array}$ & $\begin{array}{c}\varepsilon_{f, 3} \\
{[-]}\end{array}$ \\
\hline 0 & {$[0-15[$} & Cf30 \& Cf45 & Pullout & 588 & 803 & 360 & 0.030 & 0.090 & 0.600 \\
30 & {$[15-45[$} & Cf30 & Rupture & 453 & 679 & 905 & 0.016 & 0.050 & 0.200 \\
& Cf45 & Pullout & 588 & 803 & 360 & 0.030 & 0.090 & 0.600 \\
60 & {$[45-75[$} & Cf30 \& Cf45 & Rupture & 283 & 362 & 656 & 0.020 & 0.160 & 0.400 \\
\hline
\end{tabular}

Table 3: Number of fibres and orientation factor at the crack surface of the embedded fibre meshes used for obtaining the distinct numerical curves.

\begin{tabular}{r|cc|cc|ccc|cc}
\hline Test/Series & \multicolumn{4}{|c|}{ Tensile } & \multicolumn{4}{c}{ Bending } \\
Numerical curve & A & B & A & B & A 430 & B & A & B \\
\hline Number of fibres & 30 & 26 & 50 & 63 & 142 & 105 & 171 & 193 \\
Orientation factor & 0.687 & 0.701 & 0.658 & 0.662 & 0.780 & 0.765 & 0.773 & 0.761 \\
\hline
\end{tabular}




\section{List of Figures}

Figure 1: Three-dimensional scheme of the crack plane: (a) stress components, displacements and coordinate systems [27], (b) fracture modes.

Figure 2: Sketch of the intersection point $P$ in the distinct domains.

Figure 3: Determination of the embedded fibre's stress - strain diagram based on the experimental pullout force - slip relationship.

Figure 4: Three-dimensional scheme of the embedded fibre intersecting an active crack ( $\mathrm{n}$ is the vector normal to the crack plane).

Figure 5: Three-dimensional finite element mesh of the cylindric specimens: (a) concrete phase, (b) fibre phase for the Cf30 series and (c) fibre phase for the Cf45 series.

Figure 6: Numerical simulation of the uniaxial tensile tests for the Cf30 series (right hand graph is a close-up of the tensile-crack opening curve's initial part).

Figure 7: Numerical simulation of the uniaxial tensile tests for the Cf45 series (right hand graph is a close-up of the tensile-crack opening curve's initial part).

Figure 8: (a) and (b) Fibres at the crack surface, respectively, for the Cf30 and Cf45 series (light grey represents the specimen's notch and dark grey squares are the fibres); (c) and (d) normal stresses for a $w=0.16 \mathrm{~mm}$, respectively for the Cf30 and Cf45 series; (e) and (f) normal stresses for a $w=2$ $\mathrm{mm}$, respectively for the Cf30 and Cf45 series.

Figure 9: Three-dimensional finite element mesh of the prismatic specimens: (a) concrete phase and (b) fibres phase (Cf30 series).

Figure 10: Numerical simulation of the three-point bending tests for: (a) Cf30 and (b) Cf45 series. 


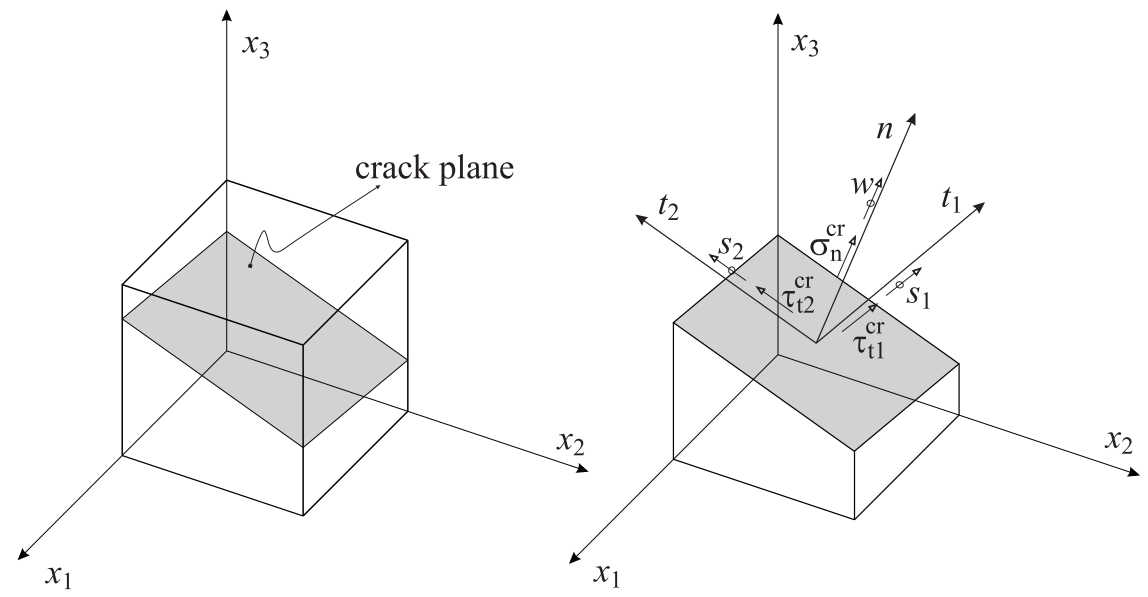

(a)
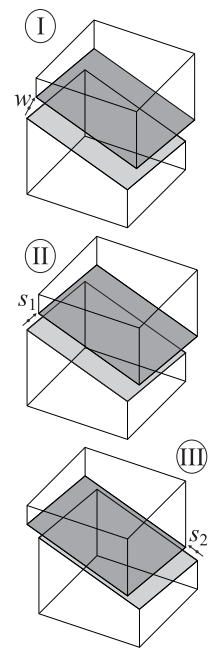

(b)

Figure 1: Three-dimensional scheme of the crack plane: (a) stress components, displacements and coordinate systems [27], (b) fracture modes. 


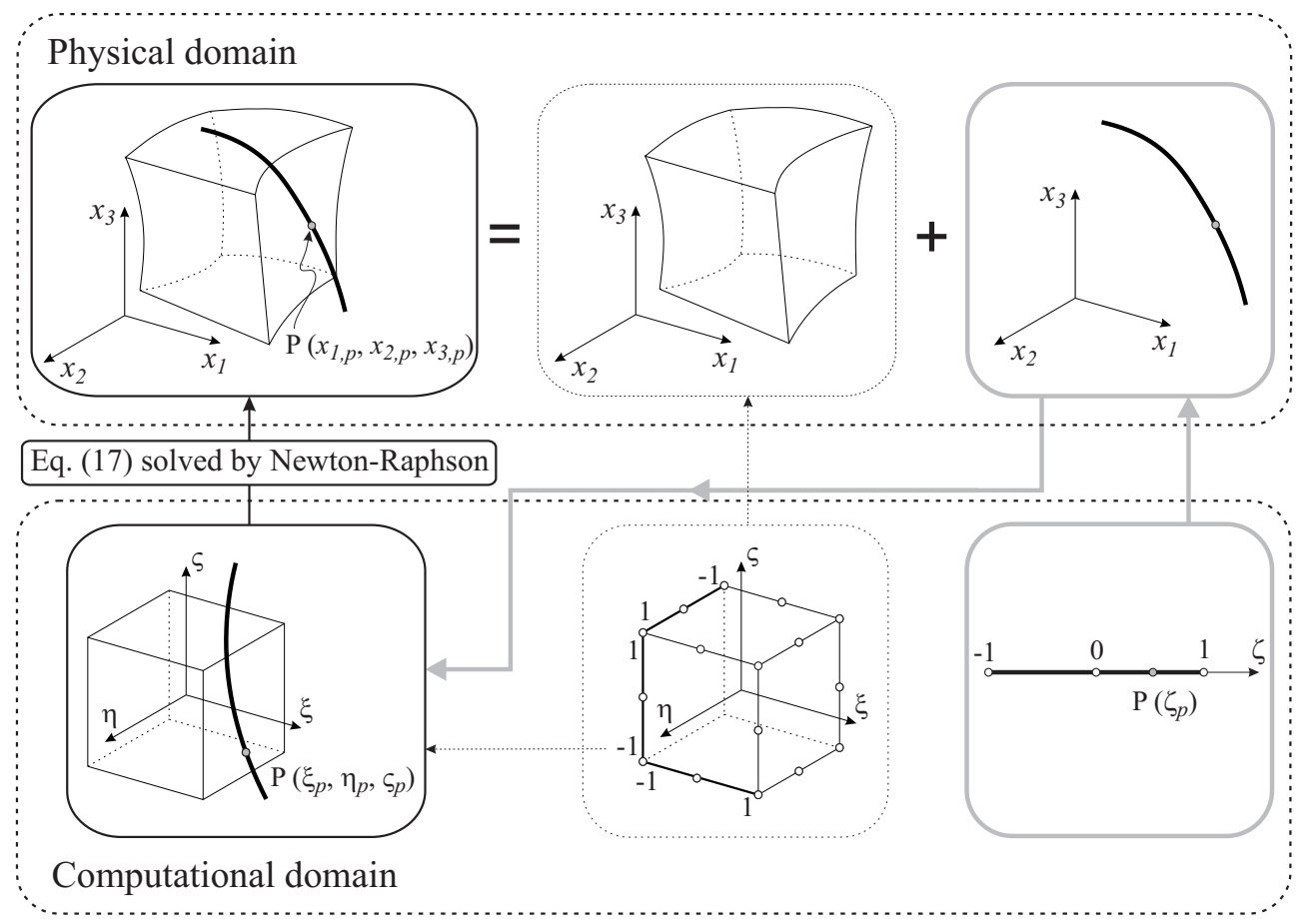

Figure 2: Sketch of the intersection point $P$ in the distinct domains.
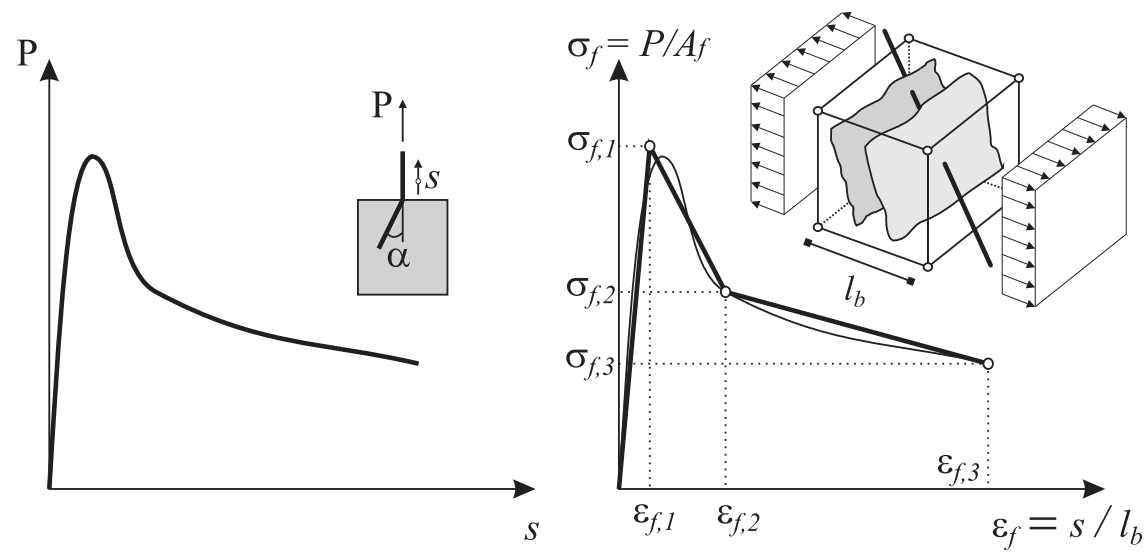

Figure 3: Determination of the embedded fibre's stress - strain diagram based on the experimental pullout force - slip relationship. 


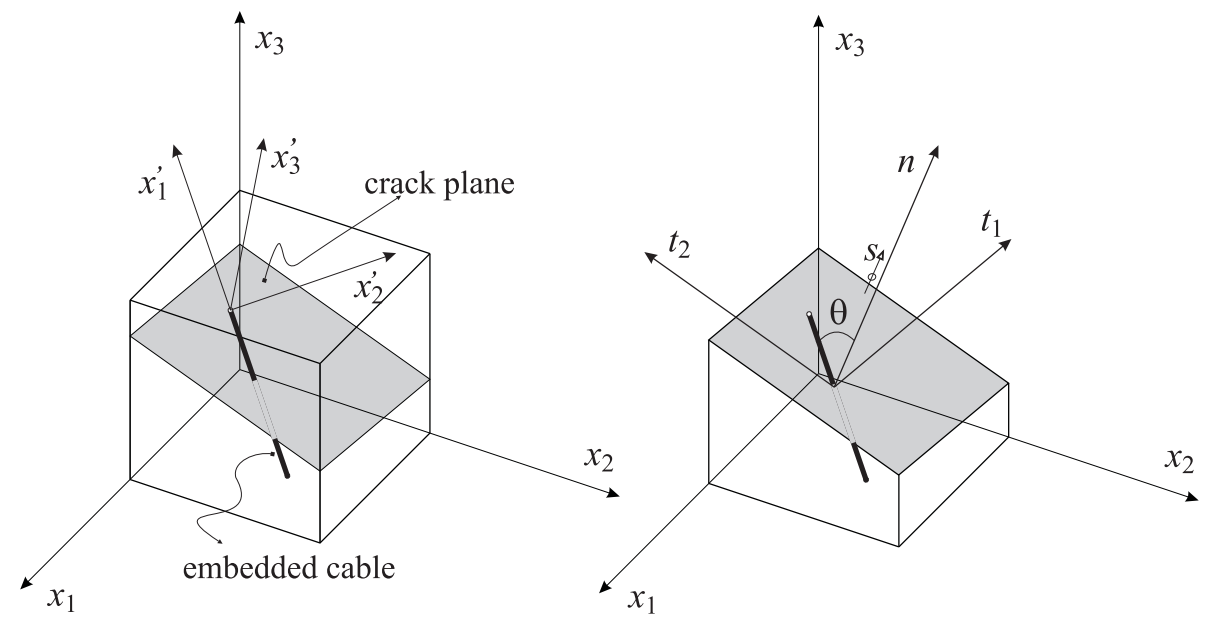

Figure 4: Three-dimensional scheme of the embedded fibre intersecting an active crack $(\hat{n}$ is the vector normal to the crack plane).

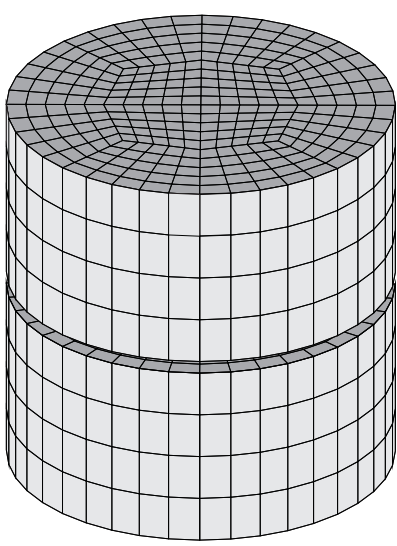

(a)

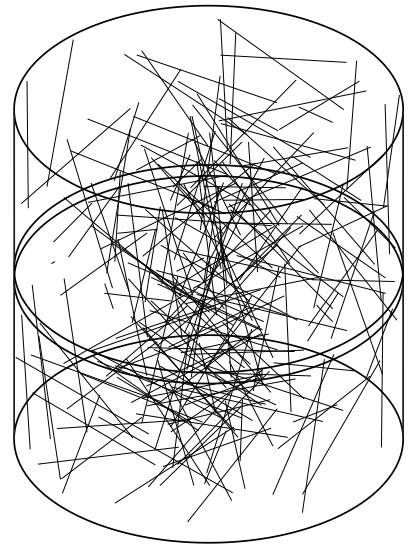

(b)

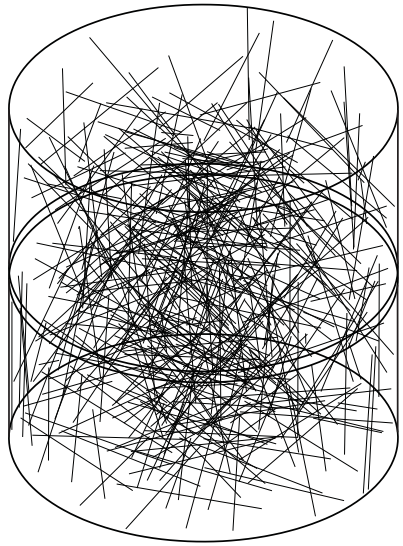

(c)

Figure 5: Three-dimensional finite element mesh of the cylindric specimens: (a) concrete phase, (b) fibre phase for the Cf30 series and (c) fibre phase for the Cf45 series. 

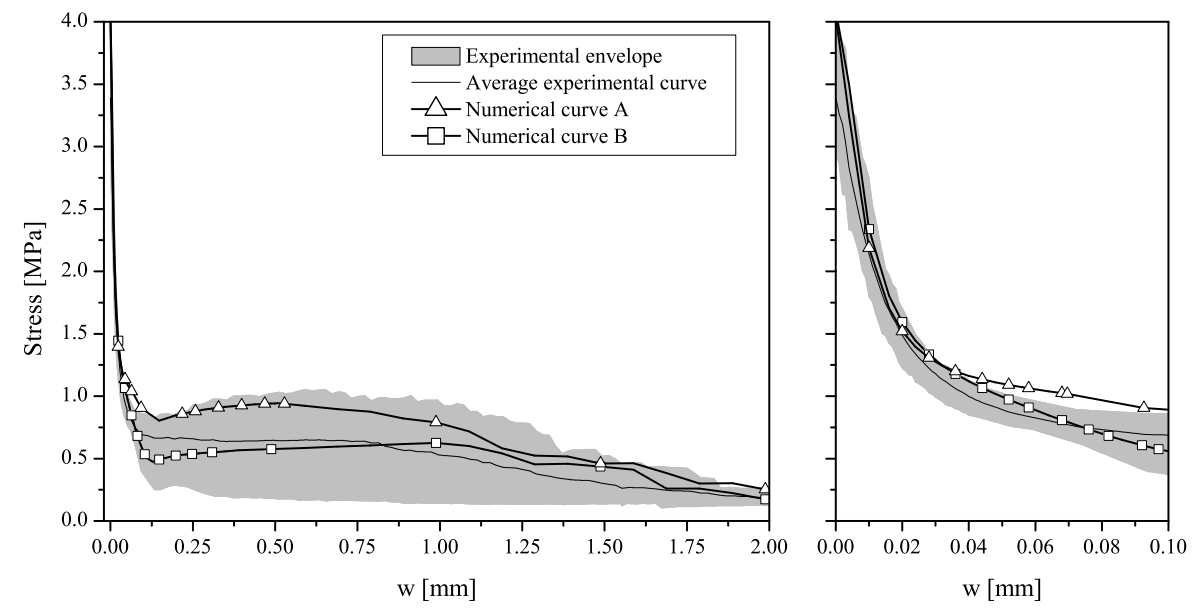

Figure 6: Numerical simulation of the uniaxial tensile tests for the Cf30 series (right hand graph is a close-up of the tensile-crack opening curve's initial part).
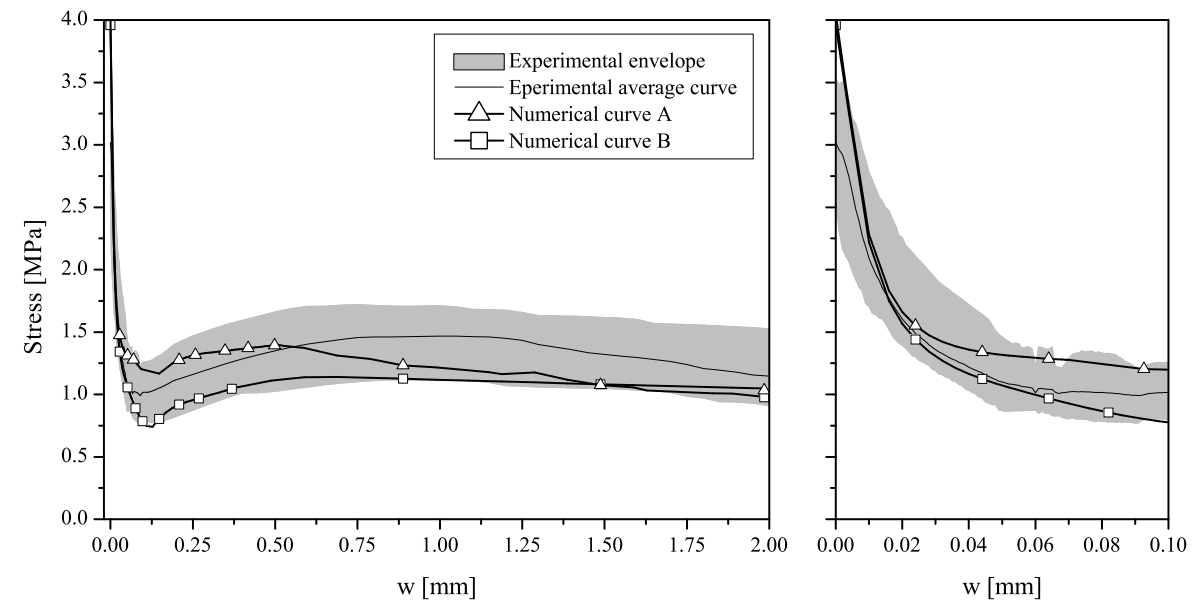

Figure 7: Numerical simulation of the uniaxial tensile tests for the Cf45 series (right hand graph is a close-up of the tensile-crack opening curve's initial part). 
Cunha, V.M.C.F.; Barros, J.A.O.; Sena Cruz, J.M. (2012)

"A finite element model with discrete embedded elements for fibre reinforced composites." Computers \& Structures, Vols. 94-95, 22-33

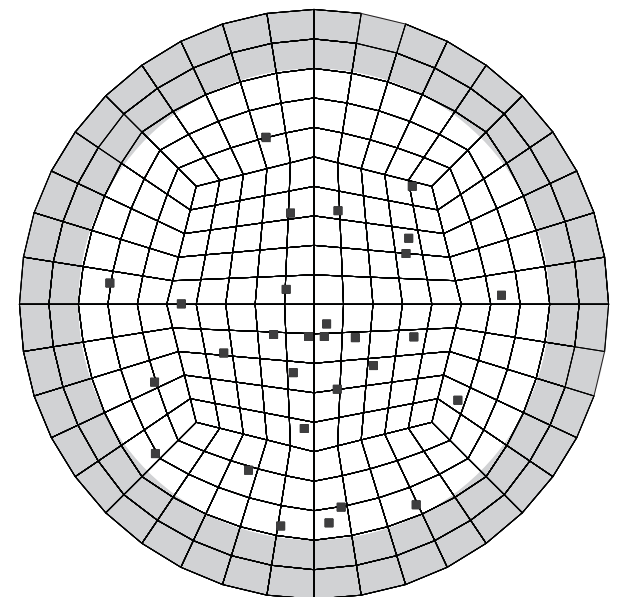

(a)

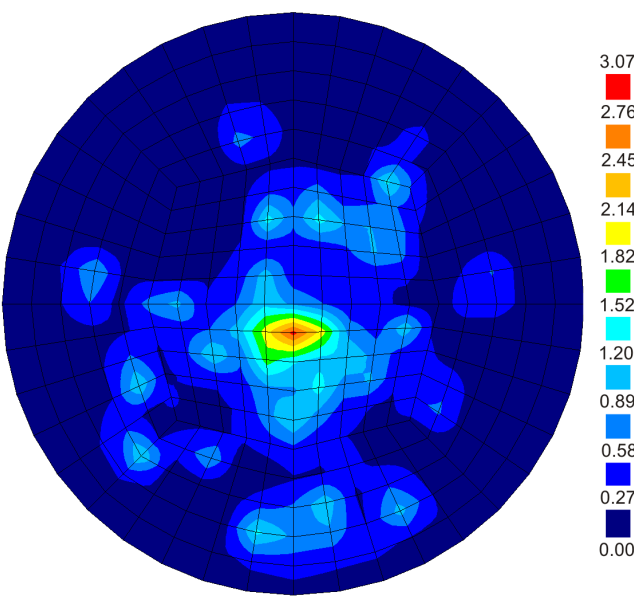

(c)

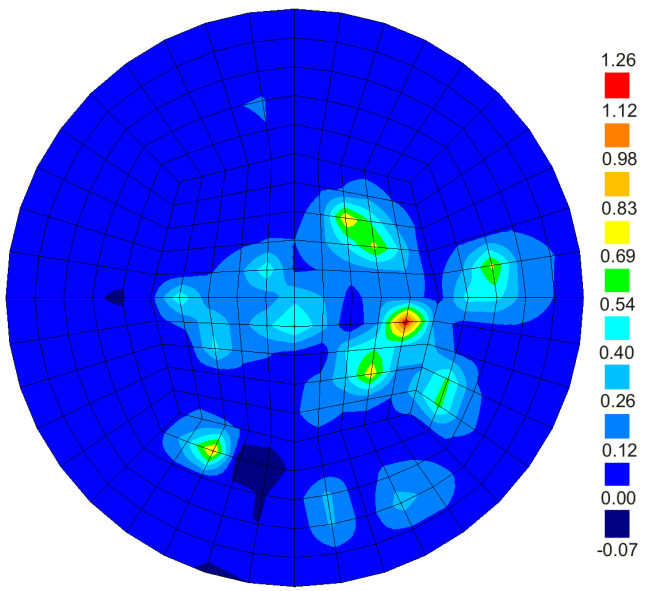

(e)

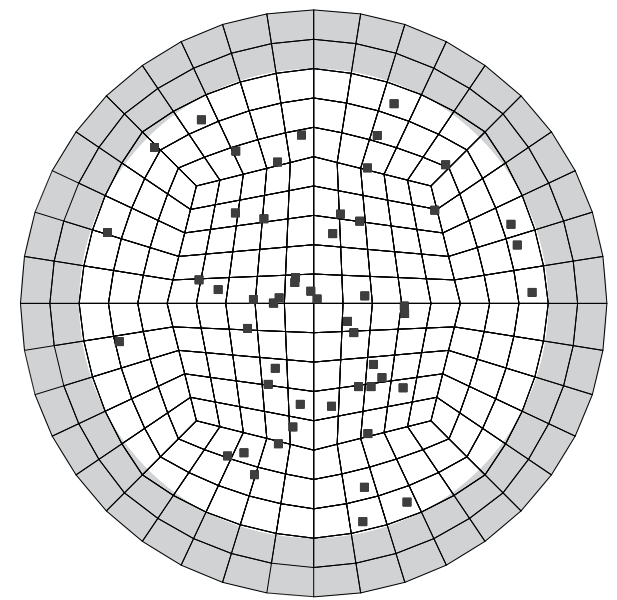

(b)

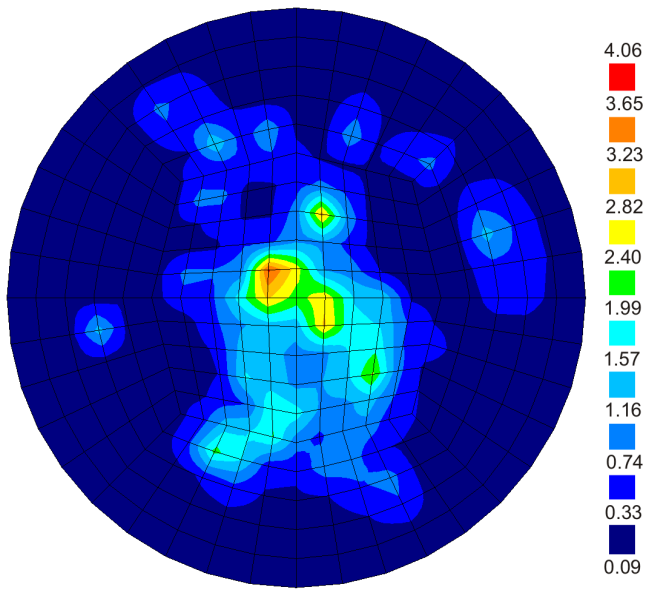

(d)

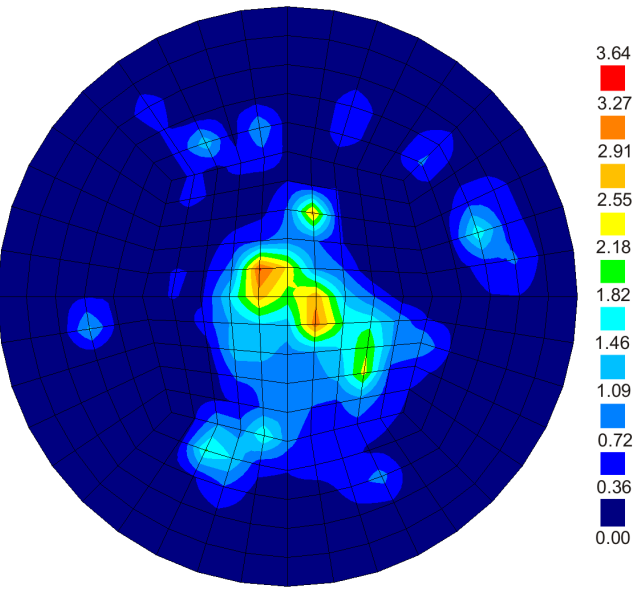

(f)

29

Figure 8: (a) and (b) Fibres at the crack surface for the Cf30 and Cf45 series, respectively (light grey represents the specimen's notch and dark grey squares are the fibres); (c) and (d) normal stresses for a $w=0.16 \mathrm{~mm}$ for the Cf30 and Cf45 series, respectively; (e) and (f) normal stresses for a $w=2 \mathrm{~mm}$ for the Cf30 and Cf45 series, respectively. 
Cunha, V.M.C.F.; Barros, J.A.O.; Sena Cruz, J.M. (2012)

"A finite element model with discrete embedded elements for fibre reinforced composites." Computers \& Structures, Vols. 94-95, 22-33

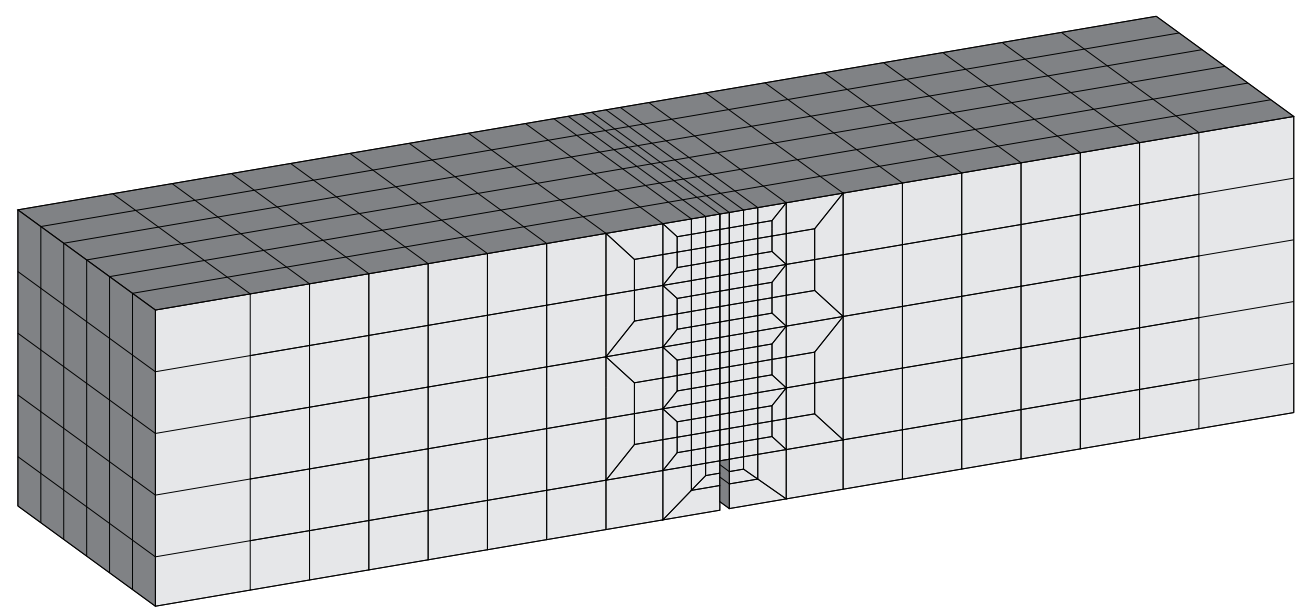

(a)

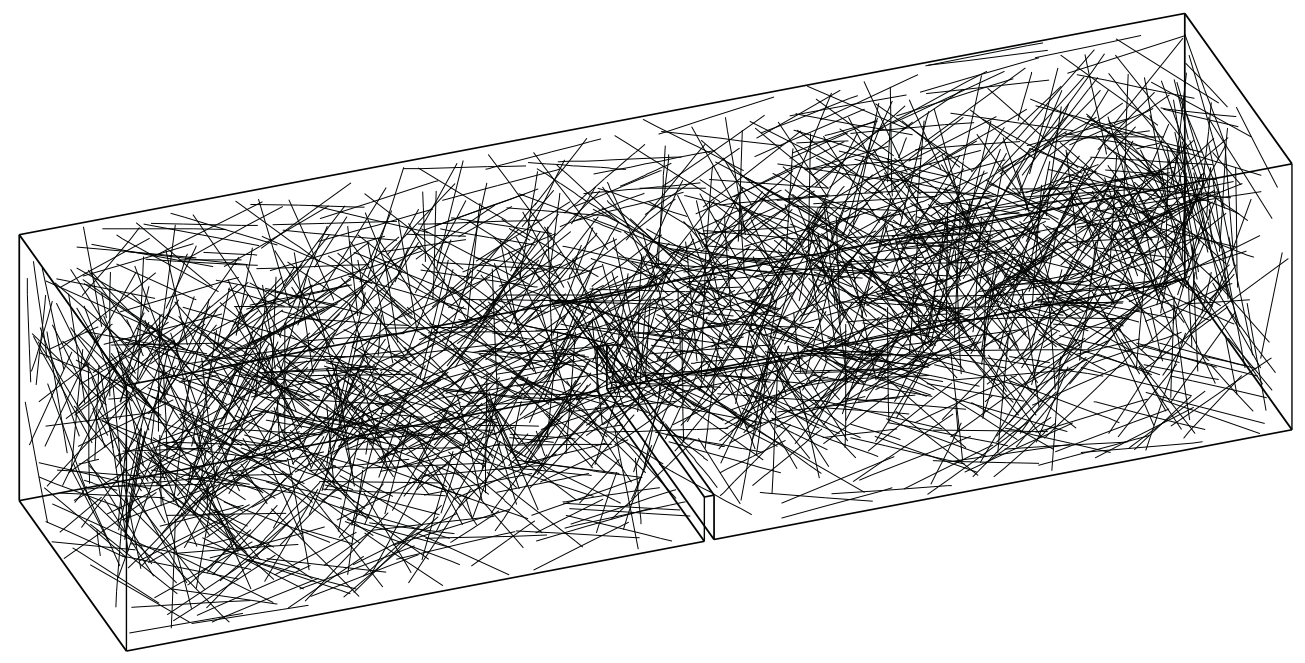

(b)

Figure 9: Three-dimensional finite element mesh of the prismatic specimens: (a) concrete phase and (b) fibres phase (Cf30 series). 
Cunha, V.M.C.F.; Barros, J.A.O.; Sena Cruz, J.M. (2012)

"A finite element model with discrete embedded elements for fibre reinforced composites." Computers \& Structures, Vols. 94-95, 22-33

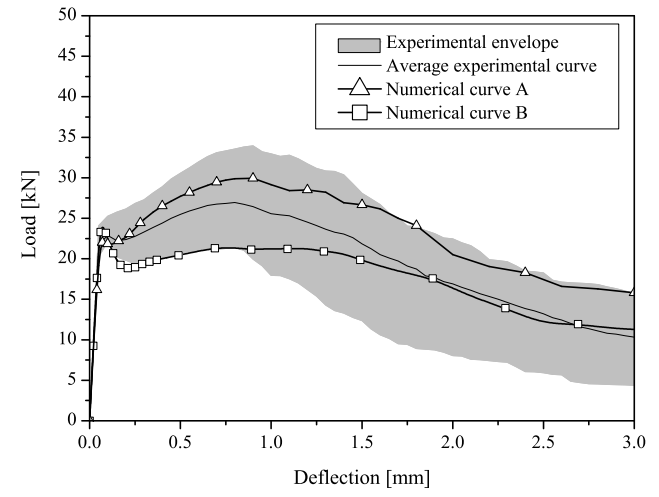

(a)

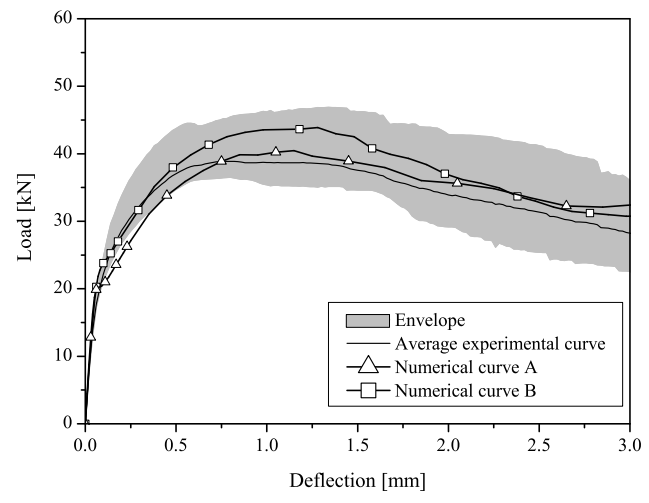

(b)

Figure 10: Numerical simulation of the three-point bending tests for: (a) Cf30 and (b) Cf45 series. 


\section{Appendix A. Derivation of Eq. 10, after [26, 28]}

The constitutive matrix for the elasto-cracked concrete, $D^{\text {crco }}$, can be obtained by the following procedure. Firstly, by incorporating Eqs. 2 and 5 into Eq. 7 yields,

$$
\Delta \underline{\sigma}=\underline{D}^{c o}\left(\Delta \underline{\varepsilon}-\left[\underline{T}^{c r}\right]^{T} \Delta \underline{\varepsilon}_{l}^{c r}\right)
$$

Pre-multiplying both members of Eq. A.1 by the crack strain transformation matrix, $\underline{T}^{c r}$, leads to

$$
\underline{T}^{c r} \Delta \underline{\sigma}=\underline{T}^{c r} \underline{D}^{c o} \Delta \underline{\varepsilon}-\underline{T}^{c r} \underline{D}^{c o}\left[\underline{T}^{c r}\right]^{T} \Delta \underline{\varepsilon}_{l}^{c r}
$$

On the other hand, the relationship between the incremental local crack stress vector, $\Delta \underline{a}_{l}^{c r}$, and the incremental stress vector in global coordinate system, $\Delta \underline{\sigma}$, can be defined as:

$$
\Delta \underline{\sigma}_{l}^{c r}=\underline{T}^{c r} \Delta \underline{\sigma}
$$

Substituting Eq. A.3 into the left member of Eq. A.2 renders,

$$
\Delta \underline{\sigma}_{l}^{c r}+\underline{T}^{c r} \underline{D}^{c o}\left[\underline{T}^{c r}\right]^{T} \Delta \underline{\varepsilon}_{l}^{c r}=\underline{T}^{c r} \underline{D}^{c o} \Delta \underline{\varepsilon}
$$

The incremental crack strain vector in the local crack coordinate system is obtained by including Eq. 8 into the left side of Eq. A.4,

$$
\Delta \underline{\varepsilon}_{l}^{c r}=\left(\underline{D}^{c r}+\underline{T}^{c r} \underline{D}^{c o}\left[\underline{T}^{c r}\right]^{T}\right)^{-1} \underline{T}^{c r} \underline{D}^{c o} \Delta \underline{\varepsilon}
$$

At last, the constitutive law of the elasto-cracked concrete is obtained by substituting Eq. A.5 in A.1, which yields:

$$
\Delta \underline{\sigma}=\left(\underline{D}^{c o}-\underline{D}^{c o}\left[\underline{T}^{c r}\right]^{T}\left(\underline{D}^{c r}+\underline{T}^{c r} \underline{D}^{c o}\left[\underline{T}^{c r}\right]^{T}\right)^{-1} \underline{T}^{c r} \underline{D}^{c o}\right) \Delta \underline{\varepsilon}
$$

or

$$
\Delta \underline{\sigma}=\underline{D}^{c r c o} \Delta \underline{\varepsilon}
$$

${ }_{635}$ where $\underline{D}^{\text {crco }}$, Eq. 10 , is the constitutive matrix for the elasto-cracked concrete. 